GRASAS Y ACEITES 68 (4)

October-December 2017, e222

ISSN-L: 0017-3495

doi: http://dx.doi.org/10.3989/gya.0664171

\title{
Oxidation kinetics of hazelnut oil treated with ozone
}

\author{
H. Uzun ${ }^{凶}$ and E. Ibanoglu \\ Gaziantep University, Department of Food Engineering, 27310 Gaziantep, Turkey \\ ${ }^{\square}$ Corresponding author: hicranuzun@gantep.edu.tr
}

Submitted: 10 June 2017; Accepted: 15 September 2017

SUMMARY: The present study investigates the oxidation kinetics of hazelnut oil ozonated in different treatment periods (1, 5, 60 and $180 \mathrm{~min})$. The kinetic rate constant $(k)$ was taken as the inverse of oxidation onset time $\left(T_{o}\right)$ observing a linear relationship from the plot of $\ln T_{o}$ to isothermal temperatures $(373,383,393$, and $403 \mathrm{~K})$ carried out at differential scanning calorimetry. Kinetic parameters, activation energy $\left(E_{a}\right)$, activation enthalpy $\left(\Delta H^{*}\right)$ and entropy $\left(\Delta S^{*}\right)$ were calculated based on the Arrhenius equation and activated complex theory. $k$ values showed an exponential rise with the increase of ozone treatment time. The increase in $k$ correlated well with the increase in the peroxide and free fatty acid values of all samples. $E_{a}$ and $\Delta H^{*}$ of the ozone treated oils showed a reducing trend and reflected an increased oxidation sensitivity after ozone treatment. Consistently, an increase in $\Delta S^{*}$ indicated a faster oxidation reaction with an increase in ozone exposure time. However, no significant difference was observed in $k, E_{a}, \Delta H^{*}, \Delta S^{*}(p<0.05)$ as a function of storage period, after the hazelnut oil was treated with ozone for $1 \mathrm{~min}$.

\section{KEYWORDS: DSC; Hazelnut oil; Kinetics of oxidation; Ozone}

RESUMEN: Cinética de oxidación del aceite de avellana tratado con ozono. El presente estudio investiga la cinética de oxidación del aceite de avellana ozonizado durante diferentes períodos (1, 5, 60 y $180 \mathrm{~min})$. La constante de velocidad cinética $(\mathrm{k})$ se tomó como la inversa del tiempo de inicio de la oxidación (To) observando una relación lineal cuando se representa el lnTo con las temperaturas isotérmicas (373, 383, 393 y $403 \mathrm{~K}$ ) llevadas a cabo en calorimetría de barrido diferencial. Los parámetros cinéticos, energía de activación (Ea), entalpía de activación $\left(\Delta H^{*}\right)$ y entropía $\left(\Delta S^{*}\right)$ se calcularon sobre la base de la ecuación de Arrhenius y de la teoría compleja activada. Los valores de $\mathrm{k}$ mostraron un aumento exponencial con el aumento del tiempo de tratamiento de ozono. El aumento de k se correlacionó bien con el aumento de peróxidos y de los ácidos grasos libres de todas las muestras. Ea y $\Delta H^{*}$ de los aceites tratados con ozono mostraron una tendencia reductora que refleja una mayor sensibilidad a la oxidación de los aceites después del tratamiento con ozono. Consistentemente, un aumento de $\Delta S^{*}$ indicó una reacción de oxidación más rápida con un aumento del tiempo de exposición al ozono. Sin embargo, no se observó diferencia significativa en $\mathrm{k}, \mathrm{Ea}, \Delta H^{*}, \Delta S^{*}(\mathrm{p}<0.05)$ en función del período de almacenamiento, después de que el aceite de avellana fue tratado con ozono durante $1 \mathrm{~min}$.

PALABRAS CLAVE: Aceite de avellanas; Cinética de oxidación; DSC; Ozono

ORCID ID: Uzun H http://orcid.org/0000-0003-1098-3197, Ibanoglu E http://orcid.org/0000-0003-2665-7919

Citation/Cómo citar este artículo: Uzun H, Ibanoglu E. 2107. Oxidation kinetics of hazelnut oil treated with ozone. Grasas Aceites 68 (4), e222. http://dx.doi.org/10.3989/gya.0664171

Copyright: (C) 2017 CSIC. This is an open-access article distributed under the terms of the Creative Commons Attribution (CC-by) Spain 3.0 License. 


\section{INTRODUCTION}

The requirement for novel preservation technologies in food processing arises from consumer preferences for minimally processed foods, which are free of chemicals, microbial spoilage and foodborne pathogens. Pulsed electric field (Sanz-Puig et al., 2016), ultrasound (Charoux et al., 2017), high intensity pulsed light (Miller et al., 2012), irradiation (Song et al., 2006), and high hydrostatic pressure (Ross et al., 2003) are technological processes with high investment costs for controlling the microbial load. In addition to them, sanitizers, bleaching agents, and chemical preservatives are used in industrial processing (Marriott, 1994). However, an unsafe use of chemicals increases the risk of environmental hazards. An alternative method in the processing of foods is the use of ozone as an antimicrobial agent (Guzel-Seydim et al., 2004). Ozone treatment reduces the population of a wide range of microorganisms even at low concentrations due to its potential oxidizing capacity. It received the GRAS (generally recognized as safe) status for use as disinfectant and sanitizer in 1997 (USDA, 1997). There are many applications for ozone in the food industry such as food surface hygiene, sanitation of food plant equipment, reuse of waste water (Yang and Chen, 1979). In the processing and storage of nuts, ozone would be recommended as a potent disinfectant, effective against a wide spectrum of microorganisms present on the surface (Oner and Demirci, 2016). Ozone would reduce the microbial population and the likelihood of mycotoxin production in nuts which causes economical loss during storage and exportation. However, food materials have complex structures which may include lipid components and ozone oxidation of these components during treatment is likely to occur and this manifests itself as a change in the physical and chemical properties of food. Recent studies investigated the antibacterial and fungicidal effects of ozonated vegetable oils (Skalska et al., 2009, Moureu et al., 2016) and their physical properties and functional groups (Sadowska et al., 2008, Sega et al., 2010). Unsaturated triglycerides, which are rich in nuts, are sensitive and susceptible to ozone oxidation which causes quality change. The hazelnut is one of the major products in Turkey, and enjoys a high economic value. It may provide a good medium for the production of mycotoxins during transportation and manufacturing after its hard shell is removed. Therefore, the use of ozone in the processing of hazelnuts is an effective method for preventing microbial growth. Although the efficiency of ozone depends largely on the method used, ozone concentration, medium, exposure time, diffusivity of ozone to food, temperature, and lipid content can be considered as a sensitive component which is susceptible to oxidation during the ozone exposure of hazelnuts. Hazelnut oil is rich in monounsaturated (MUFA) and polyunsaturated (PUFA) (approximately, 83\% MUFA and 9\% PUFA) fatty acids (Alasalvar et al., 2003), even though it has been reported to have high oxidative stability due to its high $\alpha$-tocopherol content (Parcerisa et al., 2000). Therefore, determining the effect of ozone treatment on a lipid component might be useful to predict changes in hazelnut upon ozonation. The mechanism in which gaseous ozone reacts with unsaturated triglycerides is known as Criegee reactions (Criegee, 1975) (Figure 1). Ozonolysis achieves oxidative scission of $\mathrm{C}=\mathrm{C}$ double bonds. An unstable primary ozonide initially forms and then decomposes to a zwitterionic compound which returns to a cyclic trioxolane in an anhydrous environment or a series of aldehydes or ketones with water. Criegee intermediates are highly reactive and can undergo $\mathrm{O}$ atom elimination, ester and acid formation, and hydroperoxide formation (Sega et al., 2010).

The oxidation of ozone treated vegetable oils can be expressed by a mathematical expression. Since the oxidative reactions of vegetable oils are unique in their behavior, an appropriate model must be derived individually for each product rather than a general mathematical model developed to simulate the lipid oxidation data (Tan et al., 2001). The kinetic model approach is a common method for the deterioration by environmental and compositional factors (Van Boekel, 1996). The determination of kinetic parameters of lipid oxidation in vegetable oil quality would be needed to predict quality changes, and would allow the optimization of storage conditions. One of the main environmental factors that affects quality loss is temperature, which causes the thermal oxidative decomposition of oils and fats. Recently, Differential Scanning Calorimetry (DSC) has been a commonly used technique for the

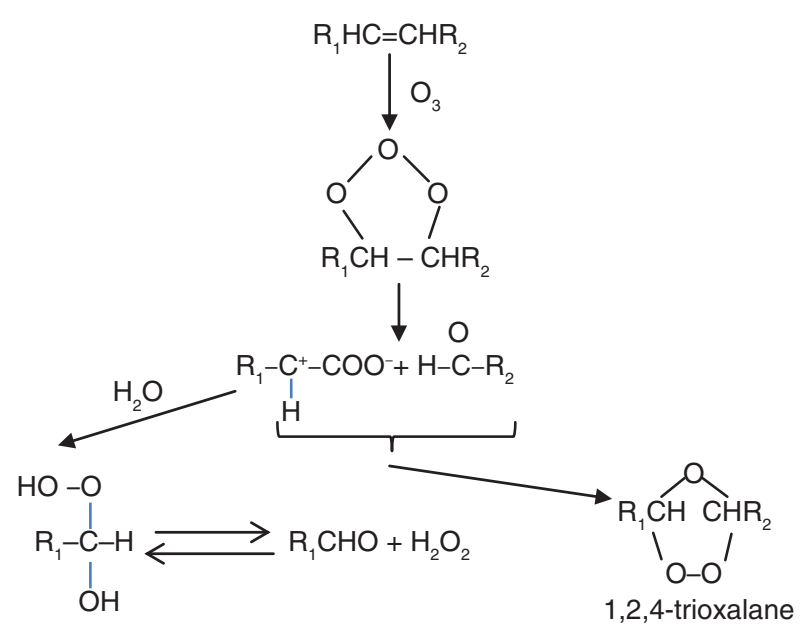

FIGURE 1. Proposed mechanisms of ozonolysis and compounds formed by the ozonolysis of unsaturated fatty acids (Criegee, 1975). 
determination of the oxidative stability of different types of oils (Tan and Che Man, 1999), because it is precise and sensible. It rapidly produces results and requires less sample without the use of toxic chemicals. The oxidative stability can be detected by DSC at isothermal modes with purified oxygen as purge gas. In general, the time before a dramatic increase in the rate of oxidation is a measure of oxidative stability and is referred to as induction period (Micic et al., 2015). The induction period is expressed as the period of time necessary for the secondary oxidation products to be formed in the chain reactions of autooxidation. The exothermic reaction of oil and oxygen is observed as a dramatic increase in the heat along with the appearance of a sharp exothermic curve in DSC. The DSC method can provide valuable data to calculate kinetic parameters for lipid oxidation such as oxidation rate constant at various temperatures and activation energy, which in turn expresses the oxidative stability by a derived mathematical relationship.

The use of ozone gas in the processing and storage of grains and nuts to prevent possible microbial contamination is considered as an alternative method (Prakash, 2013). The objective of the present work was to investigate the oxidation stability of hazelnut oil after being treated with ozone, assuming that hazelnut oil is prone to oxidation primarily in the whole hazelnut kernel. Thermal oxidation kinetics were evaluated. Kinetic parameters including activation energy $\left(E_{a}\right)$, the rate constant $(k)$, activation enthalpy $\left(\Delta H^{*}\right)$ and activation entropy $\left(\Delta S^{*}\right)$ were determined. A mathematical model was developed to express the oxidation reaction rate as a function of temperature for ozonated hazelnut oil.

\section{MATERIAL AND METHODS}

\subsection{Materials}

Crude hazelnut oil was purchased from a local manufacturer (FISKOBIRLIK Company, production year 2013). Acetic acid (100\%) and chloroform $(99.5 \%)$ were purchased from Merck Company. Potassium iodide, sodium thiosulfate, starch, and sodium hydroxide were bought from Riedel de Haen and ethanol (99.8\%) and diethyl ether (99.5\%) were obtained from Sigma-Aldrich. All chemicals used were of analytical grade.

\subsection{Ozonation of hazelnut oil}

Ozone gas was generated by an ozone generator (Ozone Marine, OMS Model, Izmir, Turkey) operating according to the corona-discharge method at a constant flow rate of $1 \mathrm{~kg} / \mathrm{min}$. The oxygen required for ozone generation was provided from the air. In each ozone treatment, a $100 \mathrm{~mL}$ of hazelnut oil sample placed into a gas washing bottle. The bottle was kept in a water bath at $20^{\circ} \mathrm{C}$ until the equilibrium was established. Ozone treatment of the sample was carried out at $20^{\circ} \mathrm{C}$. Ozone gas was directed into the bottle through flexible tubing and bubbled through the oil sample. Hazelnut oil samples were ozonated for different periods of time $(1,5,60$, and $180 \mathrm{~min})$. For each treatment period several $100 \mathrm{~mL}$ samples, 1500 $\mathrm{mL}$ hazelnut oil in total were ozonated. Ozonated samples were mixed together, kept in a dark room for 20 hours at $20^{\circ} \mathrm{C}$ and then filled into $100 \mathrm{~mL}$ hermetically sealed bottles with $2 \mathrm{~mL}$ head space. The bottles were stored in a dark room at $20^{\circ} \mathrm{C}$ for 150 days. Samples were analyzed at different time intervals $(3,7,10,20,30,40,55,70,85,100$, 125 , and 150 days) throughout the storage period to determine the oxidation rate as short and long term storage. One bottle was used for the analyses conducted at a specific storage period.

\subsection{Chemical analyses}

The peroxide value (PV) and free fatty acid value (FFA) of the oil samples were determined using the American Oil Chemists' Society official methods (Cd 8-53 and Ca50-40, respectively) (Firestone, 1993). The data given are the average of triplicate results.

\subsection{Differential scanning calorimeter}

The oxidation stability of ozone treated hazelnut oil was determined by DSC (Perkin-Elmer DSC 6 equipped with a Pyris software Perkin-Elmer Inc., Wellesley USA). The equipment was calibrated with pure indium and the baseline was obtained with an aluminium pan. An oil sample of ca. 5.0 \pm 0.5 mg was weighed into an open aluminium pan. The sample pan was placed in the sample chamber. An empty open aluminium pan was used as reference. Oxygen gas (99.8\% purity) was passed through the chamber at a rate of $50 \mathrm{ml} / \mathrm{min}$. DSC was run at different isothermal temperatures $(100,110,120$, and $\left.130{ }^{\circ} \mathrm{C}\right)$. The onset time $\left(T_{o}\right)$ of the oxidation reaction (so-called oxidative induction time) was determined from the resulting curve as the intersection of the extrapolated baseline and the tangent line (leading edge) of the exotherm. All DSC experiments were performed in triplicate and the average value of $T_{o}$ was used in calculations (Figure 2).

\subsection{Kinetic analysis of data}

The lipid oxidation in DSC was conducted with a large excess of oxygen generated by a constant flow rate which allows the formation of oxidation products regardless of the oxygen concentration (Pardauil et al., 2011). This allows the assumption 


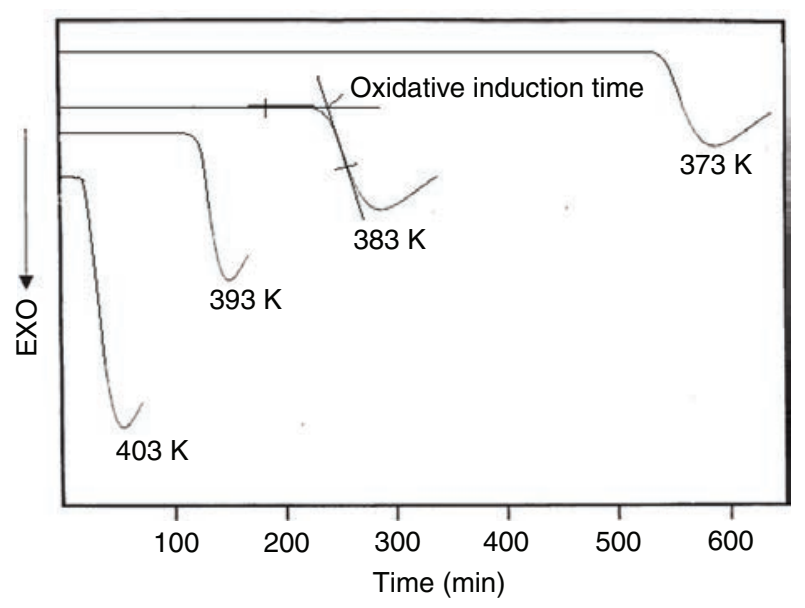

FIGURE 2. Differential scanning calorimetric oxidation curve of ozone treated hazel nut oil at 373, 383, 393, $403 \mathrm{~K}$, with an oxygen $(99.5 \%$ purity) flow rate of $50 \mathrm{~mL} / \mathrm{min}$. Y-axis indicates the exothermic heat flow.

of a first order oxidation reaction of oil in DSC at isothermal mode in many works (Pardauil et al., 2011; Tan et al., 2001; Tan and Che Man, 1999; Micic et al., 2015). The value of heat evolved at time $t$ is proportional to the amount of reacted substrate (Thurgood et al., 2007). The same extent of conversion reached is observed as oxidation induction period at different temperatures. Therefore the induction time which reflects the effect of temperature is proportional to the rate constant. Kinetic parameters including activation energy $\left(E_{a}\right)$, the rate constant $(k)$, activation enthalpy $\left(\Delta H^{*}\right)$ activation entropy $\left(\Delta S^{*}\right)$ were calculated by methods modified from (Tan et al., 2001). The relationship between isothermal temperatures and the kinetic rate constant of lipid oxidation was illustrated by the Arrhenius equation:

$\ln (k)=\ln A-E_{a} / R T \quad / 3 /$

where $k$ is the rate constant and determined as reciprocal $T_{o}, A\left(\mathrm{~h}^{-1}\right)$ is the pre-exponential factor or frequency factor, $E_{a}\left(\mathrm{~kJ} \mathrm{~mol}^{-1}\right)$ is the activation energy, $R\left(8.314510 \mathrm{~J} \mathrm{~K}^{-1} \mathrm{~mol}^{-1}\right)$ is the molar gas constant and $T(\mathrm{~K})$ is the absolute temperature. A linear least squares regression of $\ln (k)$ vs. $1 / T$ exhibits activation energy and frequency factor from the slope and intercept, respectively. The regression of $\ln (k)$ vs. $1 / T$ in the equation derived from activated complex theory gives enthalpy of activation $\left(\Delta H^{*}\left(\mathrm{~kJ} \mathrm{~mol}^{-1}\right)\right)$ and entropy of activation $\left(\Delta S^{*}(\mathrm{~J}\right.$ $\left.\mathrm{K}^{-1} \mathrm{~mol}^{-1}\right)$ ) from the slope and interface, respectively,

$\ln (k / T)=\left(\ln k_{B} / h+\left(\Delta S^{\dagger} / \mathrm{R}\right)\right)-\left(\Delta H^{\dot{t}} / R\right)(1 / T)$

where $k_{B}$ is the Boltzmann constant $(1.380658 \times$ $\left.10^{-23} \mathrm{~J} \mathrm{~K}^{-1}\right)$ and $h$ is Planck's constant $(6.6260755 \times$ $\left.10^{-34} \mathrm{~J} \mathrm{~s}\right)$. indicates the activated complex formed in a bimolecular reaction.

\subsection{Statistical analysis}

Kinetic parameters were analyzed using one-way ANOVA for the comparison of means and significant differences were determined at $95 \%$ confidence interval by Duncan's multiple range test. The linear regression analyses for fitting the kinetic data were applied by using SPSS statistical package (2013), (IBM SPSS Statistics for Windows, Version 22.0. Armonk, NY: IBM Corp.) Two-way ANOVA was applied to PV and FFA data (Table 1) to see whether an interaction was present between ozone treatment period and storage time. The interaction between ozonation period and isothermal temperature was analyzed by applying two-way ANOVA to $k$ data (Table 2). The confidence interval was $95 \%$.

\section{RESULTS AND DISCUSSION}

\subsection{Peroxide (PV) and free fatty acid value (FFA)}

Peroxide and acid values for the untreated and ozone treated hazelnut oils are shown in Table 1. The first row in the table represents the variation in PV and FFA of the control oil and ozone treated oil samples immediately after ozonation. The others indicate the PV and FFA of oil samples measured after being stored for predetermined periods. All PV and FFA values in Table 1 were statistically analyzed and they showed significant differences $(p<0.05)$. An exponential increase in the PV of oil samples with the increase in ozone treatment time was observed. While the PV of untreated oil was measured as $12.1 \mathrm{meq} / \mathrm{kg}$ oil, PV were $15.91,33.72$, 120.63 , and $207.25 \mathrm{meq} / \mathrm{kg}$ oil for $1,5,60$, and $180 \mathrm{~min}$ ozone treated samples, respectively. The increase in PV with respect to the untreated sample is 17 times after 180 min ozone treatment. The PV of oil is used as a measurement of the extent to which oxidative rancidity reactions have occurred during ozone treatment. As the treatment time is extended, more ozone molecules contact the oil sample, whose volume is kept constant in each ozone treatment, causing an extensive oxidation. The PV of ozone treated oil samples correlates well with data in previous studies on different vegetable fats and oils in relation to the ozone treatment time (Sadowska et al., 2008). The reaction of ozone with vegetable oils occurs almost exclusively with the carbon-carbon double bonds in unsaturated fatty acids. This reaction produces several oxygenated compounds such as hydroperoxides, ozonides, aldehydes, peroxides, diperoxides and polyperoxides (Bailey, 1982). Hence, the chemical and structural properties of the oils can change. Researchers stated a higher PV in ozone treated soybean oil as compared to olive oil which could be explained by the presence of a high proportion of unsaturated fatty acid chains in soybean oil than olive oil (Sadowska et al., 2008). 


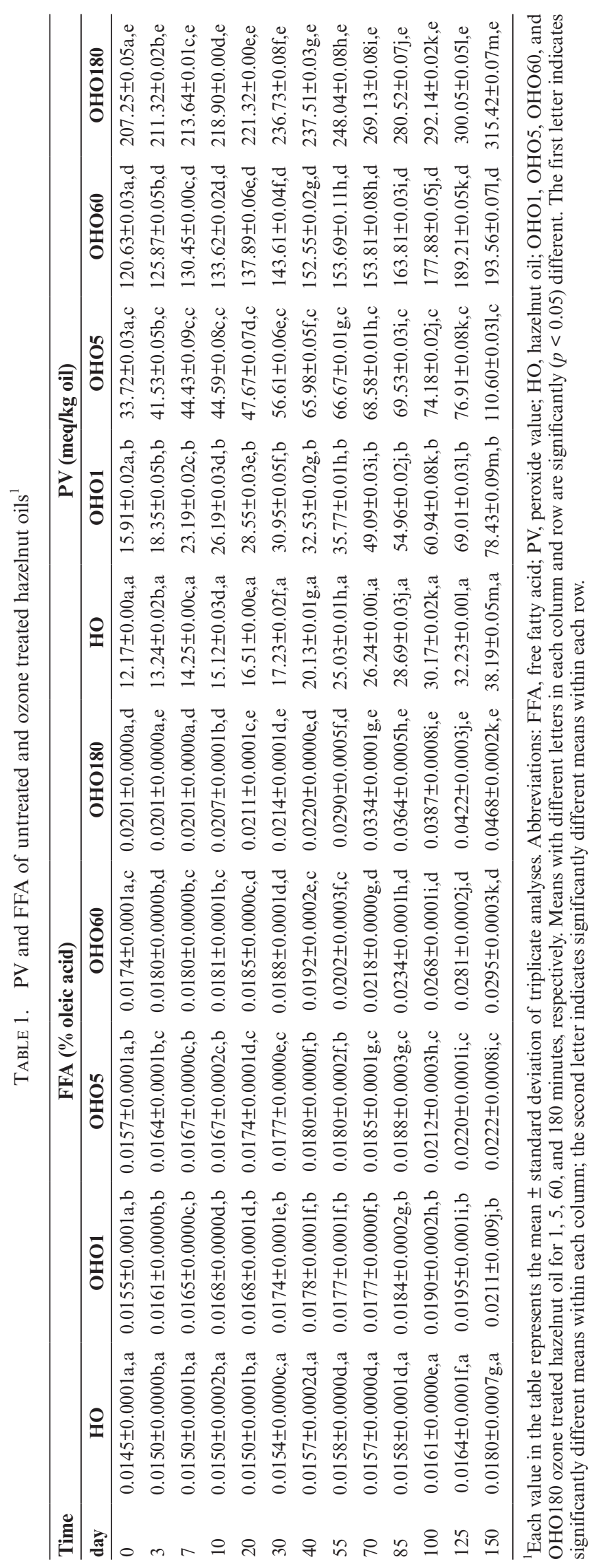


TABLE 2 The reaction rate constant $(k)$ of untreated and ozone treated hazelnut oils ${ }^{1}$ at different isothermal temperatures

\begin{tabular}{lcccc}
\hline \multicolumn{5}{c}{ Reaction rate constant at different isothermal temperatures, $\boldsymbol{k}\left(\mathbf{x 1 \mathbf { 1 } ^ { \mathbf { 3 } } \mathbf { m i n } ^ { - \mathbf { 1 } } )}\right.$} \\
\hline HO & $\mathbf{3 7 3} \mathbf{~ K}$ & $\mathbf{3 8 3} \mathbf{~}$ & $\mathbf{3 9 3} \mathbf{~ K}$ & $\mathbf{4 0 3} \mathbf{~}$ \\
OHO1 & $1.80 \pm 0.05 \mathrm{a}, \mathrm{a}$ & $3.70 \pm 0.2 \mathrm{~b}, \mathrm{a}$ & $7.80 \pm 0.3 \mathrm{c}, \mathrm{a}$ & $16.90 \pm 2.1 \mathrm{~d}, \mathrm{a}$ \\
OHO5 & $2.07 \pm 0.7 \mathrm{a}, \mathrm{b}$ & $4.12 \pm 0.9 \mathrm{~b}, \mathrm{~b}$ & $8.28 \pm 1.2 \mathrm{c}, \mathrm{b}$ & $16.94 \pm 1.5 \mathrm{~d}, \mathrm{~b}$ \\
OHO60 & $7.02 \pm 0.8 \mathrm{a}, \mathrm{c}$ & $14.11 \pm 2.3 \mathrm{~b}, \mathrm{c}$ & $28.20 \pm 0.8 \mathrm{c}, \mathrm{c}$ & $56.49 \pm 2.7 \mathrm{~d}, \mathrm{c}$ \\
OHO180 & $12.80 \pm 1.1 \mathrm{a}, \mathrm{d}$ & $25.68 \pm 3.2 \mathrm{~b}, \mathrm{~d}$ & $51.65 \pm 0.9 \mathrm{c}, \mathrm{d}$ & $103,62 \pm 4.2 \mathrm{~d}, \mathrm{~d}$ \\
\hline
\end{tabular}

${ }^{1}$ Each value in the table represents the mean \pm standard deviation of triplicate analyses. Abbreviations: HO, hazelnut oil; OHO1, OHO5, OHO60, and OHO180 ozone treated hazelnut oil for 1, 5, 60, and 180 minutes, respectively. Means with different letters in each column and row are significantly $(p<0.05)$ different. The first letter indicates significantly different means within each row; the second letter indicates significantly different means within each column.

Ozone treated and untreated samples were stored in a dark place at $20^{\circ} \mathrm{C}$ for up to 150 days. This period was assumed to be long enough to observe the oxidative changes (Seydim and Ertekin, 2006). It was observed that the PV of ozone treated oil samples raised with the increase in storage period. The increase in PV in 150 days was observed to be 3.13 times in untreated oil. The raise in PV in ozonated oil samples were found as 4.92, 3.27, 1.60, and 1.52 times for $1,5,60$ and 180 min ozone treatments, throughout the same storage period, respectively. The increase in PV was observed to slow down in 60 and 180 min ozone treatments, since the oxidation of oil was expected to be accomplished during ozone treatment. The reaction rate decreases because of the double bond disappearance with extended treatment time (Zanardi et al., 2008). It was observed statistically that there was no interaction between ozone treatment period and storage time $(\mathrm{p}<0.05)$.

As well as PV, FFA of oils is very important in terms of quality measurements in the food industry. FFA is a measurement of the oil's chemical degradation; as the oil degrades more fatty acids are freed from the glycerides, increasing the level of free acidity and thereby increasing rancidity. In the present study, the FFA of oil samples was measured as a function of ozone treatment period and also, as a function of storage time (Table 1). As seen in the table, while the FFA value of the untreated oil sample was measured as $0.0145 \%$ oleic acid, the FFA of ozone treated oils were $0.0155,0.0157$, 0.0174 and $0.0201 \%$ oleic acid for $1,5,60$, and 180 min ozone treatment, respectively. The FFA of the oil samples was observed to increase as much as $1.06,1.08,1.20$, and 1.38 times in ozone treated samples for $1,5,60$, and 180 min ozone treatment, respectively. An increase in the FFA value correlates well with the increase in PV in the ozone treatment process. In a previous study (Skalska et al., 2009), it was noticed that the acidity value of sunflower oil increased with an increase in ozone dosage. Also, it was reported that the fatty acid was oxidized rapidly and the acid value and peroxide value increased when peanuts were treated with high concentrations of ozone for a long time (Chen et al., 2014). A rise in the FFA of the oil samples was observed when they were measured throughout the storage period. The FFA of untreated oil increased 1.24 times in 150 days, whereas the FFA of the ozonated oil samples increased 1.36, 1.41, 1.69 , and 2.32 times for $1,5,60$, and $180 \mathrm{~min}$ ozone treatments, respectively. As expected, the highest FFA value was seen in the oil sample ozonated for $180 \mathrm{~min}$ and stored for 150 days (Table 1), resulting from a high amount of ozone exposure. Recently, it has been reported that partial hydrolysis that takes place during the ozonation process gives rise to unbound fatty acids which give fats an acidic feature (Skalska et al., 2009). In addition, all oils and fats, depending on minor components such as moisture and other impurities together with storage temperature, air (oxygen) concentration, and light can exhibit oxidation during storage (Syed, 2016) which is likely to release free fatty acids (Fu et al., 2016). In a recent study, it has been revealed that monounsaturated the fatty acid contents of soybean, canola, and corn oils were slightly increased during storage exhibiting a common trend which was an increase in the relative content of monounsaturated fatty acids and a decrease in that of polyunsaturated fatty acids (Syed, 2016). Considering that, fat molecules which were already exposed to oxidation with ozone, might be more sensitive to oxidation during storage as a result of structural changes. This may cause an inevitable increase in FFA values after the storage period. Four classical ozonolysis products of oleic acid were determined as azelaic acid, 9-oxononanoic acid, nonanoic acid and nonanal together with other more volatile products (Zahardis et al., 2006). It has been stated that degradation products may not only be the short chain fatty acids, peroxidic species can be degraded into carboxylic acids (Zanardi et al., 2008). Therefore, the formation of carboxylic acids may reflect an increase in FFA value. 


\subsection{DSC kinetics}

The oxidative stability of ozone treated hazelnut oil was evaluated using kinetic parameters, the rate constant $(k)$, the activation energy $\left(E_{a}\right)$, activation enthalpy $\left(\Delta H^{*}\right)$, activation entropy $\left(\Delta S^{*}\right)$. The ozonation process was carried out at $20^{\circ} \mathrm{C}$, because the solubility of oxygen decreases by almost $25 \%$ for each $10{ }^{\circ} \mathrm{C}$ rise in temperature (Tan et al., 2001). Oleic acid is the main unsaturated component in hazelnut oil. The ozonation time for the complete consumption of carbon-carbon bonds has been reported to be $2.26 \mathrm{~h}$ for oleic acid, and up to 20 h for oils (Sadowska et al., 2008). For the ozone oxidation to be accomplished, the samples were kept in a dark environment for 20 hours at $20{ }^{\circ} \mathrm{C}$ before the analyses were conducted. The stability of ozone oxidized hazelnut oil to thermal oxidative decomposition was carried out at high isothermal temperatures in DSC. The oxygen was kept in large excess providing that the concentration of it was very high compared to the amount of oil. The substrate concentration remains nearly constant for the reaction allowing the assumption that the reaction is a first order reaction which is an essential assumption for the calculation of kinetic parameters (Micic et al., 2015). The DSC method allows the detection of energy necessary for the transfer of oxygen molecules to an unsaturated fatty acid which was observed as an exothemic change. The oxidative stability of the oils was estimated on the basis of the oxidation induction time $\left(T_{0}\right)$ (Tan and Che Man, 1999) detected from the resulting thermogram at different isothermal temperatures $(373,383,393$, and $403 \mathrm{~K}$ ). Figure 2 shows the curves of oxidation at which the induction period was observed as the intersection of the extrapolated baseline and the tangent line to the leading edge. The thermal oxidation rate constant $(k)$ of untreated and ozone treated hazelnut oil samples was determined as the reciprocal of induction time, considering that $T_{0}$ is proportional to the effect of temperature on the rate of thermal lipid oxidation as the concentration is assumed to be constant.

Table 2 shows the change in the $k$ values of untreated and ozone treated hazelnut oils at isothermal temperatures applied in DSC. Those $k$ values of oil samples were analyzed statistically with respect to isothermal temperature and with respect to ozone treatment time separately, and found to be significantly different $(p<0.05)$. Also, there was statistically no interaction between isothermal temperature and ozonation period $(p<0.05)$. A dramatic increase in rate constant was observed as the isothermal temperature was increased for each ozonated sample. $k$ values also showed an exponential rise with the increase in ozone treatment time. At $373 \mathrm{~K}, k$ value increased almost 10 times with ozone treatment of 180 minutes. Commonly, edible oils with high degrees of unsaturation are more susceptible to ozone oxidation. The content of oleic acid (C18:1) in hazelnut oil has been found to range between $73.48 \%$ to $81.57 \%$ (Balta et al., 2006).

It has been detected that the unsaturated fatty acid composition of the oils decreases with ozone treatment (Thurgood et al., 2007). This has been confirmed by the measurement of iodine value in our study and it was found that the iodine value of the untreated oil and 1,5,60 and $180 \mathrm{~min}$ ozone treated oil were 95.47, 72.08, 65.09, 22.30 and 18.27 (g/100g oil), respectively. However, a discrepancy was observed between the iodine value and the oxidation reaction rate constant obtained by thermal analysis. Although the iodine value of the untreated hazelnut oil was high, it showed almost 10 times slower oxidation rate as compared to $180 \mathrm{~min}$ ozone treated hazelnut oil (Table 2). This may be explained by the presence of a high free fatty acid content which was exposed due to partial hydrolysis taking place during the ozonation process (Skalska et al., 2009). This was also evidenced by increased FFA in ozonated samples (Table 1). It has been found (Tan et al., 2001) that unbound fatty acids are more prone to oxidation compared to fatty acids bound to the glycerol backbone.

Although it is known that a higher level of unsaturation favors the oxidation process, the presence of antioxidants plays an important role in the rate of lipid oxidation. Tocopherols are very efficient antioxidant agents and $\alpha$-tocopherol is a major antioxidant in nature and donates hydrogen in the hydroxyl group to the lipid peroxyl radical. $\alpha$-Tocopherol prevents the propagation step of lipid oxidation and slows down the rate of lipid oxidation. Researchers investigated the tocopherol contents of oil extracted from different nuts and found that vitamin $\mathrm{E}$ was highest in hazelnut oil (33.1 $\mathrm{mg} \alpha$-tocopherol equivalents/100 g oil) (Kornsteiner et al., 2006). Therefore, the chemical composition influences the oxidative stability of a given oil, which, in turn, appears to be a comprehensive tool in an assessment of the multi-faceted oil quality. The antioxidative effectiveness of $\alpha$-tocopherol depends on the concentration of tocopherol. $\alpha$-Tocopherol at low concentrations acts as an antioxidant, but at high concentrations, it acts as a pro-oxidant (Jung and Min, 1990) which is clearly manifested by the increased oxidation rate during the induction period, but it may or may not be related to the length of the induction period. This behavior was suggested to be evaluated as the ratio of induction period in the presence and absence of the antioxidant, which is more critical, and the ratio of the rate of oxidation in the presence and absence of the antioxidant (Kamal-Eldin and Budilarto, 2015). The proposed mechanisms for the pro-oxidant behavior of tocopherols at high concentration are chain transfer reactions by the tocopheroxyl radical to abstract a hydrogen atom from fatty acid 
or hydroperoxide, auto-initiation by the decomposition of hydroperoxide, formation of intermediate radicals, and reactions of the oxidized products of tocopherols (Chapman et al., 2009). The loss of antioxidant efficacy and the reduction in the rate of oxidation reaction may make the evaluation of lipid oxidation by the kinetic approach difficult. However, in the interpretation of the oil oxidation stability through kinetic parameters few assumptions have been taken into consideration. The threshold concentration of tocopherol for the pro-oxidant behavior is $1 \mathrm{mmole} / \mathrm{L}$ (Naumov and Vasil'ev, 2003), which is more than the tocopherol content in the hazelnut oil. The reaction rate between $\alpha$-tocopherol and a radical is 10000 times greater than that between the radical and another lipid molecule and heating at high temperature caused rapid tocopherol degradation (Chapman et al., 2009), which increases the probability of tocopherol degradation mainly in the ozonolysis of oil rather than in the thermal oxidation by DSC. Therefore, the results presented exhibit a good approximation for the prediction of the oxidative stability of the ozone treated hazelnut oil.

Table 3 shows the changes in $k, E_{a}, \Delta H^{t}, \Delta S^{t}$ of ozonated hazelnut oil as a function of storage time. The kinetic parameters were calculated for oil samples ozonated for $1 \mathrm{~min}$ and stored for up to 90 days. The samples were analyzed by DSC at specific time intervals $(0,3,14,30,60$, and 90$)$ at different isothermal temperatures $(373,383,393$, and $403 \mathrm{~K})$. The statistical analysis of kinetic parameters did not show a significant difference $(p>0.05)$. The changes in $E_{a}, \Delta H^{t}, \Delta S^{t}$ during storage for 90 days were in the range of experimental error. Contrary to observations in PV and FFA which were observed to increase during storage (Table 1), kinetic parameters indicated that the storage period did not affect the temperature sensitivity or rate of oxidation reaction, and hence the quality change or deterioration of ozone treated oil samples. This may be related to the composition of oil sample that the oxidation that was detected by DSC, which might better reflect the extent of unsaturation rather than the formation of oxidation products.

Table 4 shows the changes in kinetic constants $\left(E_{\sigma}\right.$, $\Delta H^{*}, \Delta S^{*}$ ) for untreated and ozone treated hazelnut oils with respect to ozone treatment time $(1,5,60$, and $180 \mathrm{~min})$. The fitted data has a high correlation for determination $\left(R^{2}>0.96\right)$ indicating that temperature dependent oxidation of ozonated hazelnut oil could be characterized by the activation complex theory. Statistically, kinetic parameters were significantly different $(p<0.05)$ with respect to ozone treatment time. $E_{a}$ of ozone treated oils showed a reducing trend as the ozone exposure period increased. The $E_{a}$ value represents the minimum energy requirement to start the oxidation reaction (Laidler, 1987). This result indicates the increased oxidation sensitivity of oils after ozone treatment either due to the partial hydrolysis of triglycerides or by the destruction of compounds having high antioxidant activity. In a prior work, it was determined that the activation energy for the oxidation of sunflower oil was higher as the amount of artificial antioxidants were increased (Souza et al., 2004). The lower activation energy means less energy required for oxidation products to form. The $\Delta H^{t}$ of hazelnut oil was observed to decrease with increased ozone exposure. $\Delta H^{*}$ represents the difference in energy between ground state and the transition state in a chemical reaction. The higher activation enthalpy means the more energy required for the products to form in an activated state (Atkins and De Paua, 2006). In general, a reaction will take place faster if the value of $\Delta H^{*}$ and $E_{a}$ are low. $\Delta S^{*}$ is the difference between the entropy of the transition state and the sum of entropies of the reactants. In bimolecular reactions, when a complex is formed by association of two individual molecules, there may be a loss in transitional and rotational freedom. More often, there is a decrease in entropy in passing to an activated state leading to a negative $\Delta S^{\sharp}$ (Moore, 1972).

TABLE 3. Changes in kinetic parameters for $\mathrm{OHO} 1$ during storage period ${ }^{1}$

\begin{tabular}{|c|c|c|c|c|c|c|c|}
\hline \multirow{3}{*}{$\begin{array}{l}\text { Time } \\
\text { (day) }\end{array}$} & \multicolumn{6}{|c|}{ OHO1 } & \multirow{3}{*}{$\Delta S^{\dagger}\left(\mathrm{J} \mathrm{K}^{-1} \mathrm{~mol}^{-1}\right)$} \\
\hline & \multicolumn{3}{|c|}{$k\left(\mathrm{x} 10^{3} \min ^{-1}\right)$} & & \multirow[t]{2}{*}{$E_{a}\left(k^{\prime} ~ m o l^{-1}\right)$} & \multirow[t]{2}{*}{$\Delta H^{\dagger}\left(\mathrm{kJ} \mathrm{mol}^{-1}\right)$} & \\
\hline & $373 \mathrm{~K}$ & $383 \mathrm{~K}$ & $393 \mathrm{~K}$ & $403 \mathrm{~K}$ & & & \\
\hline 0 & $2.07 \pm 0.05$ & $4.15 \pm 0.5$ & $8.28 \pm 0.07$ & $16.68 \pm 0.31$ & $86.72 \pm 0.25 \mathrm{a}$ & $83.51 \pm 0.20 \mathrm{a}$ & $-74.41 \pm 0.91 \mathrm{a}$ \\
\hline 3 & $2.15 \pm 0.08$ & $4.31 \pm 0.5$ & $8.64 \pm 0.13$ & $17.42 \pm 0.27$ & $86.91 \pm 0.33 \mathrm{a}$ & $83.70 \pm 0.37 \mathrm{a}$ & $-73.56 \pm 0.55 \mathrm{a}$ \\
\hline 14 & $2.28 \pm 0.07$ & $4.57 \pm 0.5$ & $9.16 \pm 0.09$ & $18.28 \pm 0.55$ & $86.58 \pm 0.41 \mathrm{a}$ & $83.36 \pm 0.42 \mathrm{a}$ & $-73.98 \pm 1.32 \mathrm{a}$ \\
\hline 30 & $3.99 \pm 0.1$ & $7.95 \pm 0.5$ & $16.05 \pm 0.24$ & $31.54 \pm 0.62$ & $86.25 \pm 0.37 \mathrm{a}$ & $83.02 \pm 0.35 \mathrm{a}$ & $-72.87 \pm 0.75 a$ \\
\hline 60 & $4.75 \pm 0.05$ & $9.48 \pm 0.5$ & $18.97 \pm 0.23$ & $37.97 \pm 0.36$ & $86.52 \pm 0.35 \mathrm{a}$ & $83.30 \pm 0.18 \mathrm{a}$ & $-73.13 \pm 0.34 \mathrm{a}$ \\
\hline 90 & $4.84 \pm 0.09$ & $9.71 \pm 0.5$ & $19.49 \pm 0.12$ & $38.81 \pm 0.47$ & $86.68 \pm 0.45 \mathrm{a}$ & $83.46 \pm 0.23 \mathrm{a}$ & $-73.21 \pm 0.15 \mathrm{a}$ \\
\hline
\end{tabular}

${ }^{1}$ Each value in the table represents the mean \pm standard deviation of triplicate analyses. Abbreviations: OHO1, ozone treated hazelnut oil for 1 minute; $k$, reaction rate constant; $E_{a}$, activation energy; $\Delta H^{*}$, activation enthalpy; $\Delta S^{*}$, activation entropy. Means with different letters are significantly $(p<0.05)$ different within each column. 
However, an increase in $\Delta S^{t}$ was observed as the ozone exposure was increased (Table 4) indicating an increase in disorderliness in the activated complex state. A possible explanation for this is that the activated complex state for lipid oxidation in ozone treated hazelnut oil is more probable and the oxidation reaction rate is faster. These results were correlated well with change in $k$ values. It could be concluded that an increase in $k$ and $\Delta S^{t}$ and a decrease in $E_{a}$ and $\Delta H^{*}$ indicated a faster oxidation reaction when the ozone exposure time of hazelnut oil was extended.

A prediction of the oxidation induction period at any temperature could be possible by fitting the experimental data to a mathematical equation. In the present study, the regression of logarithm of $k$ and reciprocal of isothermal temperature showed a linear relationship and regression equations for untreated hazelnut oil and ozonated oil samples are given in Table 5. Correlation coefficients indicated a high degree of linear dependency between $k$ and $T$ $\left(R^{2}>0.999\right)$. These equations were used to predict $T_{o}$ during storage at $25^{\circ} \mathrm{C}$ for hazelnut oil and ozonated samples and predicted $T_{o}$ values are also included in Table 5. $T_{o}$ was found as 659 days for untreated

TABLE 4. Changes in kinetic parameters for untreated and ozone treated hazelnut oils ${ }^{1}$

\begin{tabular}{|c|c|c|c|}
\hline $\begin{array}{l}\text { Ozonation } \\
\text { time (min) }\end{array}$ & $E_{a}\left(\mathbf{k J ~ m o l}^{-1}\right)$ & $\Delta H^{\dagger}\left(\mathrm{kJ} \mathrm{mol}^{-1}\right)$ & $\Delta S^{\dagger}\left(\mathbf{J ~ K ~ K}^{-1} \mathrm{~mol}^{-1}\right)$ \\
\hline $\mathrm{HO}$ & $91.44 \pm 0.21 \mathrm{a}$ & $88.33 \pm 0.34 a$ & $-75.03 \pm 0.30 \mathrm{a}$ \\
\hline OHO1 & $87.72 \pm 0.10 b$ & $84.51 \pm 0.35 b$ & $-74.41 \pm 0.27 b$ \\
\hline OHO5 & $86.83 \pm 0.14 \mathrm{c}$ & $83.42 \pm 0.45 \mathrm{c}$ & $-64.15 \pm 0.15 c$ \\
\hline OHO60 & $85.03 \pm 0.20 \mathrm{~d}$ & $81.88 \pm 0.25 \mathrm{~d}$ & $-63.72 \pm 0.33 d$ \\
\hline OHO180 & $84.56 \pm 0.15 \mathrm{e}$ & $80.34 \pm 0.18 \mathrm{e}$ & $-62.34 \pm 0.52 \mathrm{e}$ \\
\hline
\end{tabular}

${ }^{1}$ Each value in the table represents the mean \pm standard deviation of triplicate analyses. Abbreviations: $\mathrm{HO}$, hazelnut oil; OHO1, $\mathrm{OHO}$, OHO60, and $\mathrm{OHO} 180$ ozone treated hazelnut oil for 1 , 5,60 , and 180 minutes, respectively. $E_{a}$, activation energy; $\Delta H^{\vec{t}}$, activation enthalpy; $\Delta S^{*}$, activation entropy. Means with different letters are significantly $(p<0.05)$ different within each column. hazelnut oil when oxidation was carried out at ambient temperature. In the Turkish Standard, the shelflife of hazelnut oil has been stated as a maximum of two 2 years (Turkish Standards, 2003). This correlates well with the predicted $T_{o}$. Predicted $T_{o}$ values decreased for ozone treated hazelnut oils (Table 5) which were $388,115,54$ and 38 days for 1, 5, 60 and $180 \mathrm{~min}$ ozone treated hazelnut oils, respectively. Predicted induction times for 10 different oils have been estimated through regression equations found by fitting the experimental data in accelerated shelflife testing in a previous work (Tan et al., 2001) and it has been stated that the estimated values at low temperatures can be considered as approximate values. Different reaction pathways that are followed by the lipid oxidation at high or low temperatures may be the reason together with the effects of oxygen solubility, metal catalysts and antioxidants (Thurgood et al., 2007). Moreover, the ambient conditions in storage would have a limited oxygen concentration in comparison to the oxidation stability tests conducted with $99.5 \%$ pure oxygen. Thus, predicted $T_{o}$ may reflect uncertainties which are not included in the regression equation.

It has been suggested that a high correlation existed between each of DSC parameters (peak temperature and enthalpy) and standard chemical methods including FFA, PV which are used to estimate the deterioration of edible oils (Tan and Che Man, 1999). In the present study, we noticed a considerable correlation between FFA, PV and $k$. The experimental results showed that FFA increased with the increase in reaction rate constant as the ozone treatment time was increased. Similarly, PV showed a dramatic increase with $k$ as the ozone treatment time was extended. Regression equations and the respective correlations between FFA and $k\left(\mathrm{Y}=0.951 \mathrm{X}+0.098\right.$ with $\left.R^{2}=0.961\right)$ and $\mathrm{PV}$ and $k\left(\mathrm{Y}=0.941 \mathrm{X}+3.588\right.$ with $\left.R^{2}=0.952\right)$ were verified by establishing linear regression equations at an isothermal temperature of $373 \mathrm{~K}$. A high correlation between $k$ and FFA and PV reveals that DSC is an appropriate method for determining the

TABLE 5. Regression equations between $\ln k$ and isothermal temperatures and predicted oxidation induction time $\left(T_{o}\right)$ at room temperature $(298 \mathrm{~K})^{1}$

\begin{tabular}{llcc}
\hline & \multicolumn{2}{c}{$\ln k$ vs. 1/T (temperature) } \\
\hline $\begin{array}{l}\text { Ozonation time } \\
\text { (min) }\end{array}$ & \multicolumn{1}{c}{ Regression equation ${ }^{\text {a }}$} & Correlation coefficient $R^{2}$ & $\begin{array}{c}\text { Predicted } T_{o} \text { at room temperature (298 } \\
\text { K) (day) }\end{array}$ \\
\hline HO & $\ln k=-11000(1 / T)+23.150$ & 0.9995 & 659 \\
OHO1 & $\ln k=-10431(1 / T)+21.769$ & 0.9989 & 388 \\
OHO5 & $\ln k=-10436(1 / T)+23.004$ & 0.9995 & 115 \\
OHO60 & $\ln k=-10227(1 / T)+23.052$ & 0.9995 & 54 \\
OHO180 & $\ln k=-10171(1 / T)+23.221$ & 0.9995 & 38
\end{tabular}

${ }^{1}$ Significance at $P<0.05$. Abbreviations: HO, hazelnut oil; OHO1, OHO5, OHO60, and OHO180 ozone treated hazelnut oil for 1, 5, 60 , and 180 minutes, respectively. 
extent of oxidation in oils. It can be used as a reliable, rapid method for detecting the extent of lipid oxidation.

\section{CONCLUSION}

The present study demonstrated that isothermal DSC is a useful method for determining the effect of ozone treatment on a lipid component of hazelnut upon ozonation. The method provided valuable data to calculate kinetic parameters $\left(k, \Delta S^{t}, E_{a}\right.$ and $\Delta H^{f}$ ) for lipid oxidation. A mathematical model was developed to express the oxidation reaction rate as a function of temperature for ozonated hazelnut oil. It could be concluded that increasing $k$ and $\Delta S^{t}$ and decreasing $E_{a}$ and $\Delta H^{*}$ resulted in a faster oxidation reaction when the ozone exposure time of hazelnut oil was extended.

\section{REFERENCES}

Alasalvar C, Shahidi F, Ohshim T, Wanasundara U, Yurttas HC, Liyanapathirana CM. 2003. Turkish tombul hazelnut (Corylus FFAellana L.), 2. Lipid characteristics and oxidative stability. J. Agric. Food Chem. 51, 3797-3805. http:// dx.doi.org/10.1021/jf021239x

Atkins P, De Paua J. 2006. Physical Chemistry for the Life Sciences. New York: Oxford University Press, pp. 256-259. http://dx.doi.org/10.1002/cphc.200600131

Bailey PS. 1982. Ozonation in organic chemistry, 2: Non olefinic compounds. San Diego, USA: Academic Press. http:// dx.doi.org/10.1002/ange.19840960428

Balta MF, Yarılgaç T, Asskin MA, Kuçuk M, Balta F, Özrenk K.2006. Determination of fatty acid compositions oil contents and some quality traits of hazelnut genetic resources grown in eastern Anatolia of Turkey. J. Food Compos. Anal. 19, 681-686. http://dx.doi.org/10.1016/j.jfca.2005.10.007

Chapman TM, Kim HJ, Min DB. 2009. Prooxidant Activity of Oxidized $\alpha$-Tocopherolin VegetableOils. Food Chem. 74, 536542. http://dx.doi.org/10.1111/j.1750-3841.2009.01262.x

Charoux CMG, Ojha KS, O'Donnell CP, Cardoni A, Tiwari BK. 2017. Applications of airborne ultrasonic technology in the food industry. J. Food Eng. 208, 28-36. https://doi. org/10.1016/j.jfoodeng.2017.03.030

Chen R, Maa F, Li P, Zhang W, Ding X, Zhang Q, Li M, Wanga Y, Xu,B. 2014. Effect of ozone on aflatoxins detoxification and nutritional quality of peanuts. Food Chem. 146, 284 288. http://dx.doi.org/10.1016/j.foodchem.2013.09.059

Criegee R. 1975. Mechanism of Ozonolysis. Angew. Chem. Int. Edit. 14, 745-752. http://dx.doi.org/10.1002/anie. 197507451

Firestone D. 1993. AOCS, Official methods and recommended practices of the American oil chemists' society (4th ed.), Champaign, Illinois: American Oil Chemists's Society. http://dx.doi.org/10.1002/lipi.19970990510

Fu M, Qu Q, Yang X, Zhang X. 2016. Effect of intermittent oven drying on lipid oxidation, fatty acids composition and antioxidant activities of walnut. Food Sci. Technol.LEB 65, 1126-1132.

Guzel-Seydim ZB, Greene AK, Seydim AC. 2004. Use of ozone in the food industry. Food Sci. Technol.-LEB 37,453-460. http://dx.doi.org/10.1016/j.lwt.2003.10.014

Jung MY, Min DB. 1990. Effects of $\alpha-, \gamma-$, and $\delta$-tocopherols on the oxidative stability of purified soybean oil. J. Food Sci. 55, 1464-1465. http://dx.doi.org/10.1111/j.1365-2621.1990. tb03960.x

Kamal-Eldin A, Budilarto E. 2015. Tocopherols and tocotrienols as antioxidants for food preservation. Handbook of Antioxidants for Food Preservation Elsevier, 141-159. http://dx.doi.org/10.1016/b978-1-78242-089-7.00006-3
Kornsteiner M, Wagner KH, Elmadfa I. 2006. Tocopherols and total phenolics in 10 different nut types. Food Chem. 98, 381387. http://dx.doi.org/10.1016/j.foodchem.2005.07.033

Laidler KJ. 1987. Chemical Kinetics, Harper and Row, New York. https://doi.org/10.1007/bf00327865

Marriott N.G. 1994. Principles of food sanitation (3rd ed.), Chapman \& Hall: New York, NY

Micic MM, Ostojic SB, Simonovic, MB, Krstic G, Pezo LL, Simonovic BR. 2015. Kinetics of blackberry and raspberry seed oils oxidation by DSC. Thermochim. Acta 601, 39-44. http://dx.doi.org/10.1016/j.tca.2014.12.018

Miller BM, Sauer A, Moraru CI. 2012. Inactivation of Escherichia coli in milk and concentrated milk using pulsed-light treatment. J. Dairy Sci. 95, 5597-5603. http:// dx.doi.org/10.3168/jds.2012-5714

Moore WJ. 1972. Physical Chemistry (5th ed.); London: Longman, pp. 381-387. http://dx.doi.org/10.1016/03681874(73)80218-7

Moureu S. 2016. Influence of Storage Temperature on the Composition and the Antibacterial Activity of Ozonized Sunflower Oil. Ozone-Sci. Eng. 38, 143-149. https://doi. org/10.1080/01919512.2015.1128319

Naumov VV, Vasil'ev RF. 2003. Antioxidant and pro-oxidant effects of tocopherol. Kinet. Catal. 44, 101-105. http:// dx.doi.org/10.1023/a:1022528919697

Oner ME, Demirci A. 2016. Ozone for Food Decontamination Handbook of Hygiene Control in the Food Industry pp. 491501. https://doi.org/10.1016/B978-0-08-100155-4.00033-9

Parcerisa J, Casals I, Boatella J, Codony R, Rafecas M. 2000. Analysis of olive and hazelnut oil mixtures by high-performance liquid chromatography-atmospheric pressure chemical ionisation mass spectrometry of triacylglycerols and gas-liquid chromatography of non-saponifiable compounds (tocopherols and sterols). J. Chromatogr. A 881, 149-158. http://dx.doi.org/10.1016/s0021-9673(00)00352-6

Pardauil JJR, Souza LKC, Molfetta FA, Zamian JR, Filho GNR. 2011. Determination of the oxidative stability by DSC of vegetable oils from the Amazonian area. Bioresource Technol. 102, 5873-5877. http://dx.doi. org/10.1016/j.biortech.2011.02.022

Prakash, A. 2013. Non- thermal processing technologies to improve the safety of nuts. Improving the Safety and Quality of Nuts. (Ed. L. Harris). Series in Food Science, Technology and Nutrition, Chapter 3. Woodhead Publishing Limited, pp. 35-55. https://doi.org/10.1533/9780857097484.1.35

Ross AIV, Griffiths MW, Mittal GS, Deeth HC. 2003. Combining nonthermal technologies to control foodborne microorganisms. Int. J. Food Microbiol. 89, 125-138. http:// dx.doi.org/10.1016/s0168-1605(03)00161-2

Sadowska J, Johansson B, Johannessen E, Friman R, BroniarzPress L, Rosenholm JB. 2008. Characterization of ozonated vegetable oils by spectroscopic and chromatographic methods. Chem. Phys. Lipids 151, 85-91. http://dx.doi. org/10.1016/j.chemphyslip.2007.10.004

Sanz-Puig M, Santos-Carvalho L, Cunha LM, Pina-Pérez MC, Martínez A, Rodrigo D. 2016. Effect of pulsed electric fields (PEF) combined with natural antimicrobial by-products against S. Typhimurium. Innov. Food Sci. Emerg. 37, 322-328. https://doi.org/10.1016/j.ifset.2016.09.004

Sega A, Zanardi I, Chiasserini L, Gabbrielli A, Bocci V, Travagli V. 2010. Properties of sesame oil by detailed ${ }^{1} \mathrm{H}$ and ${ }^{19} \mathrm{C}$ NMR assignments before and after ozonation and their correlation with iodine value, peroxide value, and viscosity measurements. Chem. Phys. Lipids 163,148-156. http:// dx.doi.org/10.1016/j.chemphyslip.2009.10.010

Seydim AC, Ertekin B. 2006. Effect of various packaging materials on hazelnut oil quality during storage. Süleyman Demirel Üniversitesi, Fen Bilimleri Enstitüsü Dergisi, 10, 341-345.

Skalska K, Ledakowicz S, Perkowski J, Sencio B. 2009. Germicidal Properties of Ozonated Sunflower Oil. Ozone Sci. Eng. 31, 232-237. http://dx.doi.org/10.1080/01919510902838669

Song HP, Kim DH, Jo C, Lee CH, Kim KS, Byun MW. 2006. Effect of gamma irradiation on the microbiological quality and antioxidant activity of fresh vegetable juice. Food Microbiol. 23, 372-378. http://dx.doi.org/10.1016/j. fm.2005.05.010 
Souza AG, Santos JCO, Conceição MM, Silva MCD, Prasad SA. 2004. A thermoanalytic and kinetic study of sunflower oil. Braz. J. Chem. Eng. 21, 265-273. http://dx.doi. org/10.1590/s0104-66322004000200017

Syed A. 2016. Oxidative Stability and Shelf Life of Vegetable Oils, Oxidative Stability and Shelf Life of Foods Containing Oils and Fats, pp. 187-207. https://doi.org/10.1016/ b978-1-63067-056-6.00004-5

Tan CP, Che Man YB. 1999. Differential Scanning Calorimetric Analysis for monitoring the oxidation of heated oils. Food Chem. 67, 177-184. http://dx.doi.org/10.1016/ s0308-8146(99)00115-6

Tan CP, Man CH, Selamat C, Yusoff MSA. 2001. Application of arrhenius kinetics to evaluate oxidative stability in vegetable oils by isothermal differential scanning calorimetry. J. Am. Oil Chem. Soc. 78, 1133-1138. http://dx.doi. org/10.1007/s11746-001-0401-1

Thurgood J, Ward R, Martini S. 2007. Oxidation kinetics of soybean oil/anhydrous milk fat blends: A differential scanning calorimetry study. Food Res. Int. 40, 1030-1037. http:// dx.doi.org/10.1016/j.foodres.2007.05.004

Turkish Standards. 2003. Edible Refined Hazelnut Oil, (TS 6581), Ankara, Turkish Standards Institute.
USDA. 1997. Code of Federal Regulations, Title 9, Part 381.66, poultry products; temperatures and chilling and freezing procedures. Office of the Federal Register National Archives and Records Administration, Washington, DC. https://doi. org/10.1007/978-1-4615-2059-7_4

Van Boekel MAJS.1996. Statistical Aspects of Kinetic Modelling for Food Science Problems. J. Food Sci. 61, 477-485, 489. http://dx.doi.org/10.1111/j.1365-2621.1996. tb13138.x

Yang PPW, Chen TC. 1979. Effects of ozone treatment on microflora of poultry meat. J. Food Process. Pres. 3, 177-185. http://dx.doi.org/10.1111/j.1745-4549.1979. tb00579.x

Zahardis J, La Franchi BW, Petrucci GA. 2006. Direct observations of polymerization in the oleic acid-ozone heterogenous reaction system by photoelectron resonance capture ionization aerosol mass spectrometry. Atmos. Environ. 40, 1661-1670. http://dx.doi.org/10.1016/j. atmosenv.2005.10.065

Zanardi I, TrFFAagli V, Gabbrielli A, Chiasserini L, Bocci V. 2008. Physico-Chemical Characterization of Sesame Oil Derivatives. Lipids 43, 877-886. http://dx.doi.org/10.1007/ s11745-008-3218-x 